\title{
Smart technology for the protection of urban biodiversity
}

\author{
Thi Hai Yen Pham ${ }^{1}$, Isam Shahrour ${ }^{1}$, Ammar Aljer ${ }^{1}$, Alain Lepretre ${ }^{1}$, Celine Pernin ${ }^{1}$, Sana \\ Ounaies ${ }^{1}$ \\ ${ }^{1}$ Laboratoire de Génie Civil et géo-Environnement, Université de Lille, 5900 Lille, France
}

\begin{abstract}
This paper presents the use of the smart city solution for the protection of urban biodiversity. This biodiversity is crucial for human wellbeing and sustainable development. The paper presents first the urban biodiversity, then the risk of its deterioration by urban activity (change in land-use; pollution of air, soil and water; noise pollution; light pollution; alien species; construction, flood). Finally, the paper presents briefly the Smart City solution including data collection, data analysis and reporting and control and how this solution could be used for the protection of biodiversity.
\end{abstract}

\section{Urban biodiversity}

Biodiversity is crucial to the planet equilibrium, human wellbeing and sustainable development [2]. It regulates and preserves the quality of soil and water. It contributes to the reduction of our vulnerability to natural hazards such as flood and fires. Its loss has negative impact on human health and security of food and energy and could disturb ecosystem function. Cities are huge hubs for ecosystem services with large environmental impact [5].

Urban biodiversity is the variety or richness and abundance of living organisms, including genetic variation, and habitats found in and on the edge of human settlements. Species range from rural fringe to urban core. At the landscape and habitat level it includes:

- Remnant vegetation (remnant habitats of native plant communities, rock faces)

- Agricultural landscapes (meadows, arable land)

- Urban-industrial landscapes (wastelands and vacant lots, residential areas, industrial parks, railway areas, brownfields).

- Ornamental gardens and landscapes (formal parks and gardens, small gardens and green spaces) [6]

The diversity of plants and animals in urban landscape shows interesting patterns:

- The age of the city affects species richness; old cities have more species than young cities.

- Diversity may correlate with economic wealth. For example, in Phoenix, USA, 
plant and bird diversity in urban neighbourhoods and parks shows a significant positive correlation with median family income.

- Twenty percent of the world's bird species and 5 percent of the vascular plant species are located in cities.

- Around 70 percent of the plant species and 94 percent of bird species found in urban areas are native of surrounding region [12]

Urban biodiversity provides a series of benefits (commonly termed ecosystem services) to cities ranging from the more directly perceived, such as water supplies and recreation facilities (parks) to less tangible effects of large biodiverse areas, such as hosting species which may help cure diseases or contribute to long-term climate stability [10]. Urban green areas such as parks and vegetation help microclimate regulation, tree canopy may contribute to reduce the urban heat island effect and save large amounts of energy used in air conditioning. It reduces pollution, improves air quality and enhances human well-being. Research showed that improvement of urban biodiversity impact directly both physical and mental health of citizens.

\section{Risk on urban biodiversity}

Urban biodiversity is subjected to increasing risk related to urbanization. Table 1 summarizes major risks of urbanization on the biodiversity.

Table 1: Urbanization risk on biodiversity

\begin{tabular}{|l|}
\hline Urbanization risk on biodiversity \\
\hline Land-use change \\
\hline Pollution of air, soil and water \\
\hline Noise pollution \\
\hline Light pollution \\
\hline Alien species \\
\hline Construction \\
\hline Flood \\
\hline
\end{tabular}

\subsection{Change in land-use}

Change in land-use can alter ecosystem services. Globally, the conversion of native grasslands, forests, and wetlands into croplands, tree plantations and developed areas has led to vast increase in production of food, timber, housing and other commodities, but with negative impact on ecosystem services and biodiversity [1]. Humans may destroy natural landscapes with consequences on habitat destruction and reconversion of natural habitat to human use, which are not necessarily compatible with native organisms.

\subsection{Urban pollution}

Urban pollution concerns the air, soil and water. Air pollution causes decline of majority of species. Plants are more affected than animals by the pollution. Tickle et al. (1995) showed that more than 1,300 species were threatened in Europe due to acid deposition in the 1990s, including 11 mammals, 29 birds, 10 amphibians, 398 higher plants, 305 fungi, 238 lichens and 65 invertebrates, providing the most detailed survey to date [3]. Water pollution results from various sources, such as sewage leak, industrial spills or direct discharge in water 
bodies, biological contamination and farm runoff. Water contamination has serious negative effects on all species. The degradation of local habitats through human activities cause downstream effects like leaching of harmful chemicals from mines into the water table. Water pollution can have effects on the reproductive viability of organisms. Soil pollution is mostly due to human activities such as heavy industries or use of pesticides in agriculture. Absorption of pollution by the plants may lead to alter metabolism and introduce pollution in the food chain. These processes occur with microorganisms and arthropods in a given soil environment. This may destroy some layers of the primary food chain, and thus has a negative effect on predator animal species. Small life forms may consume harmful chemicals which may then be passed in the food chain to larger animals so this may lead to increased mortality rate and even animal extinction.

Noise pollution is harmful and annoying to humans and animals. It can result from transportation, construction and human activities such as sport events or concerts. Halfwerk et al. (2011) showed that high traffic noise has an impact on avian reproduction by smaller clutches and fewer fledged chicks.

Light pollution affects many groups of animals, especially birds and nocturnal insects [4]. Patterns of reproduction can also be disturbed by light extension to new places.

\subsection{Alien species}

Alien species are introduced by humans intentionally or unintentionally into urban environment. This can negatively affect the ecosystem because the new species may outcompete native organisms and displace them. The impact could concern entire habitat. For example, when the Asian chestnut blight fungus virtually eliminated American chestnut from over 180 million acres of eastern United States forests in the first half of the 20th century, it was a disaster for many animals that were highly adapted to live in forests dominated by this tree species. Similarly, the Australian paperbark tree has replaced native plants, such as sawgrass, over 400,000 acres of South Florida, because it has a combination of traits that increases fire hazards. Many birds and mammals adapted to native plant community declined in abundance as paperbark spread [2].

\subsection{Construction activity}

Construction activity causes fragmentation and reduction of natural habitats, which could lead to the disappearance of some spices in the urban environment [10]. Consequently, any construction project in urban area should be based on analysis of its impact in urban biodiversity.

\subsection{Urban heat island}

Urban heat island results from construction and urban activities. The temperature in cities is higher than that in rural area. In rural areas, vegetation and open land typically dominate the landscape. Trees and vegetation provide shade, which helps lower surface temperatures. They also reduce air temperature through evapotranspiration, in which plants release water to the surrounding air, dissipating ambient heat. In contrast, urban areas are characterized by dry, impervious surfaces, such as conventional roofs, sidewalks, roads, and parking lots. The change in ambient temperature and humidity could affect the health of spices in cities and could cause their disappearance or departure to other familiar areas. 


\subsection{Flood}

Flood risk increases with urbanization activity. The construction activity results in largescale ground impermeabilization, which induces important increase in water runoff and could lead to flood. In addition, interception of rainfall by trees, other vegetation, and permeable soils is crucial in reducing the pressure on the drainage system and in lowering the risk of surface water flooding [9]. Urban landscapes with 50-90\% impervious ground cover can lose $40-83 \%$ of incoming rainfall to surface runoff whereas forested landscapes only lose $13 \%$ of rainfall input from similar precipitation events [8]. Flood has highly negative impact on biodiversity. It causes large scale habitat destruction, spices destruction or migration, water and soil pollution and sediment transportation. This impact is generally catastrophic for the biodiversity.

\section{Smart City solution}

The smart city solution presented in this section is inspired from the Smart City solution illustrated in Figure 2 [11]. It is based on the use of digital technology and citizens involvement for the transformation of the City into eco- and socio- friendly city with enhanced efficiency and safety.

The Smart City solution includes different tasks which are coordinated by a unique platform. Access to any task is possible only via the platform.

\subsection{Data collection}

The first task concerns data collection. This task includes collection in a digital format of data concerning the city such as urban infrastructures and buildings, urban services, population profile. These data could be collected and stored using GIS system. It includes also data from sensors, which are used to monitor urban infrastructures and services as well as the environment. These sensors record and transmit in real time data about urban system functioning. It also includes data from citizens, who can send data and information about their observations and suggestions. The platform collects also data from open-sources such as the weather, transportation, pollution and events related to urban hazards. All these data are stored into the smart city information system and updated regularly.

\subsection{Data analysis}

Data analysis includes the use of engineering, environmental, safety and information technology tools such as Artificial Intelligence (AI) to transform real-time and historical data into operational data with the objective to reinforce the efficiency and safety of urban systems and to improve the quality of life of citizens. Today, the use of AI becomes popular, because it allows learning from real data, to establish patterns of complex system behaviour, to detect rapidly abnormal events, to take mitigation measurements and to improve the system efficiency.

\subsection{Reporting and control}

Reporting and control concern the use of data analysis in operational command and to share data and analysis with authorities, staffs and citizens. It uses mainly advanced graphic tools such as 3D tools or Virtual and Augmented Reality tools to provide strong and clear messages about the observations, analyses, options, actions and feed-backs. The platform 
can operate direct control of urban systems through electronic devices (motors, breakers, switches, valves and pumps) to preserve the security and integrity of these systems as well as o increase their efficiency.

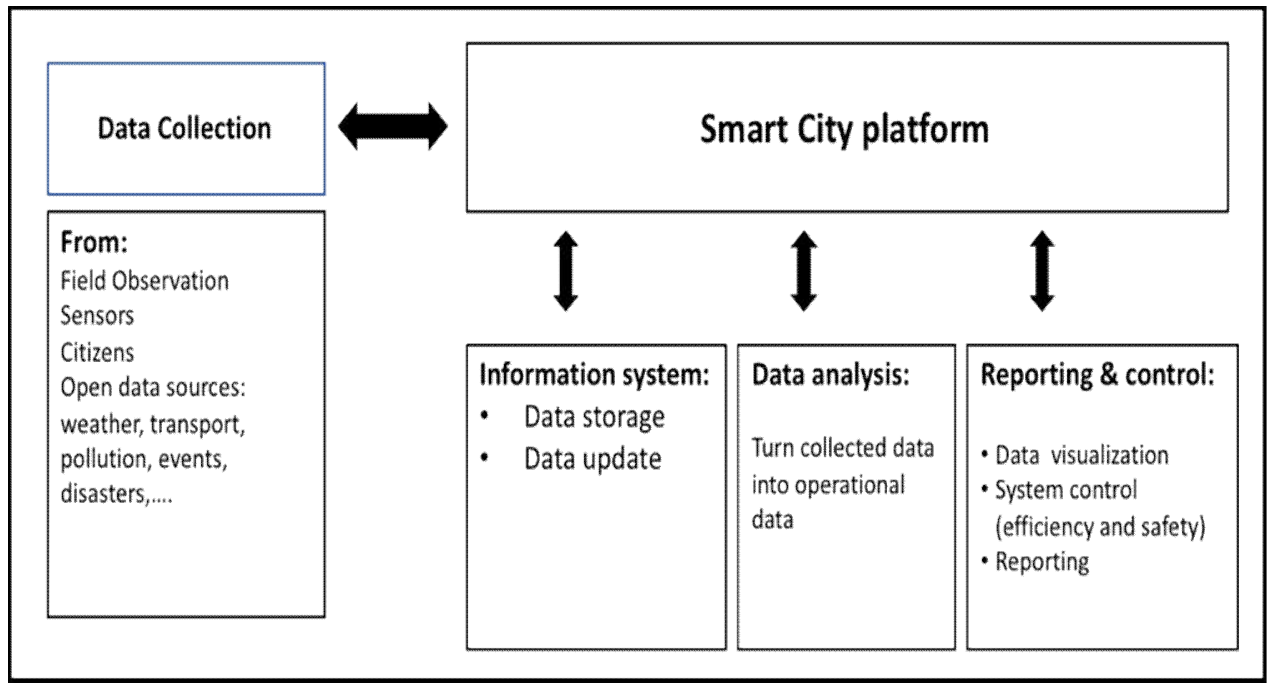

Fig.2. Smart City solution organization (Shahrour \& al. 2016)

\section{Application of Smart City solution to urban biodiversity protection}

\subsection{Data collection}

The application of the Smart City solution on urban biodiversity protection requires adaptation of the concept presented earlier to topics related to urban biodiversity such as urban spices, habitat, weather, pollution, urban hazards and human activity. The objective is to develop a long-term information system that includes the evolution of urban spices as well as major factors that affect this evolution. This approach faces a major difficulty, which is related to the time scale. Indeed, some events are rapid such as flood and weather variation, while the evolution of spices could be perceptible at long time scale, except situation of major hazards, which could have a short-time impact on spices. Table 2 shows the categories of data to be collected. It includes the following categories.

- Urban spices; this category includes inventory of urban spices and habitat with more details on specific spices (witness spices), alien spices and spices activity and health. Data are collected by field visit, by cameras installed at significant locations and from citizens involved in the project. The observation time should be established for each spice considering weather change or major events related to natural or human-made hazards.

- Weather conditions; this category concerns the hourly variation of the temperature, humidity, air quality, rainfall intensity and wind speed and direction.

- Human activity, with a focus on construction maps, change in land use, pollution of soil and water, noise pollution and light pollution.

- Urban hazards such as flood, storms, earthquakes, fire and industrial hazards. 
The collection of these data could be conducted using sensors (temperature, humidity, air quality, lighting, noise, rainfall, wind speed); others parameters require field observation or image processing of videos or photos collected by cameras.

Table 2: Data to be collected for urban biodiversity preservation

\begin{tabular}{|l|l|l|l|}
\hline Urban species & \multicolumn{1}{|c|}{ Weather conditions } & \multicolumn{1}{|c|}{ Human activities } & Urban hazards \\
\hline Inventory & Temperature & Construction & Flood \\
\hline Witness species & Humidity & Noise pollution & Storms \\
\hline Alien species & Air quality (pollution,...) & Light pollution & Earthquakes \\
\hline $\begin{array}{l}\text { Species habitat (Location, } \\
\text { continuity,...) }\end{array}$ & Rainfall & Soil, water pollution & Fires \\
\hline Species activities & Wind & Air pollution & Industrial \\
\hline Species health & & Changing in land use & \\
\hline
\end{tabular}

\subsection{Data analysis}

Data analysis includes the following:

- Analysis of spices patterns including their health and activity at regular time interval and at specific critical events (hazards). This analysis concerns spices spatial distribution as well as habitat connectivity. Change in pattern should be visualized using spatial maps (GIS) as well as quantitative indicators.

- Analysis of causal factors (weather conditions, human activity, urban hazard) using statistical methods or more advanced methods such as AI in order to identify "abnormal" as well as their amplitude and duration. These events could be characterized according to their impact by an intensity factor, which will be used in the following step.

- Correlation and causal analyses to establish relationships between the evolution of spices patterns and causal factors, characterized by their intensity.

\subsection{Reporting and control}

With time, this analysis will help to understand the impact of causal factors on urban biodiversity and to establish recommendations for authorities, managers and citizens for the protection of biodiversity. This analysis could also help in establishing resiliency stratergy for biodiversity protection including the preparation and recovery and adaptation phases.

\section{Conclusion}

This paper presented the importance of biodiversity for the global equilibrium of cities as well as for well citizens wellbeing and urban sustainable development. This biodiversity is subjected to increasing menace due to urbanization, which causes harmful impact to biodiversity such as change in land-use, pollution of air, soil and water; noise pollution; light pollution; alien species; construction and flood. It is then necessary to establish an integrated strategy, based on the Smart City solution, for the urban biodiversity preservation including data collection at different time and spatial scales concerning urban spices and their habitat as well as factors that impact these spices. Analysis of these data will help understanding the menace on biodiversity and to establish a protection and resilient strategy for urban biodiversity. 


\section{References}

1. Arico, Salvatore et al. 2005. Millennium Ecosystem Assessment, 2005. Ecosystems and Human Well-Being: Synthesis. Island Press, Washington, DC.

2. Brown, I., Ridder, B., Alumbaugh, P., Barnett, C., Brooks, A., 2Duffy, L., Webbon, C., Nash, E., Townend, I., Black, H. and Hough, R. 2012 Climate Change Risk Assessment for the Biodiversity and Ecosystem Services Sector", in Climate Change risk assessment, UK, 2012, http://www.defra.gov.uk/environment/climate/government/

3. Dudley, Nigel and Sue Stolton. 2014. "Air Pollution and Biodiversity: A Review Air Pollution and Biodiversity: A Review Nigel Dudley Sue Stolton 23 Bath Buildings, Montpelier, Bristol BS6 5PT Contact Information: Nigel Dudley, 23 Bath Buildings, Montpelier, Bristol BS6 5PT. Telephone." 6(December).

4. Eisenbeis, Gerhard and Andreas Hänel. 2009. "Light Pollution and the Impact of Artificial Night Lighting on Insects." Ecology of Cities and Towns: A Comparative Approach (Sixma 2000):243-63.

5. Elmqvist, T. et al. 2015. "Benefits of Restoring Ecosystem Services in Urban Areas." Current Opinion in Environmental Sustainability 14:101-8.

6. Güneralp, Burak et al. 2013. "Urbanization, Biodiversity and Ecosystem Services: Challenges and Opportunities." 437-52. Retrieved (http://link.springer.com/10.1007/978-94-007-7088-1).

7. Halfwerk, Wouter, Leonard J. M. Holleman, C(Kate) M. Lessells, and Hans Slabbekoorn. 2011. "Negative Impact of Traffic Noise on Avian Reproductive Success." Journal of Applied Ecology 48(1):210-19.

8. Kaye, Jason P., Peter M. Groffman, Nancy B. Grimm, Lawrence A. Baker, and Richard V. Pouyat. 2006. “A Distinct Urban Biogeochemistry?" Trends in Ecology and Evolution 21(4):192-99.

9. Pataki, Diane E. et al. 2011. "Coupling Biogeochemical Cycles in Urban Environments: Ecosystem Services, Green Solutions, and Misconceptions.” Frontiers in Ecology and the Environment 9(1):27-36.

10. Puppim de Oliveira, J. A. et al. 2011. "Cities and Biodiversity: Perspectives and Governance Challenges for Implementing the Convention on Biological Diversity (CBD) at the City Level." Biological Conservation 144(5):1302-13. Retrieved (http://dx.doi.org/10.1016/j.biocon.2010.12.007).

11. Shahrour I., O. Abbas, A. Abdallah, Y. Abou Rjeily, A. Afaneh, A. Aljer, B. Ayari, E. Farrah, D. Sakr, F. Al Masri (2017). Lessons from a Large Scale Demonstrator of the Smart and Sustainable City. In Happy City Book, A. Brdulak and H. Brdulak (eds.), Springer International Publishing AG 2017, DOI 10.1007/978-3-319-49899-7_11

12. Secretariat of the Convention on Biological Diversity. 2012. "Cities and Biodiversity Outlook: A Global Assessment of the Links between Urbanization, Biodiversity, and Ecosystem Services." Executive Summary 64. Retrieved (http://www.cbd.int/authorities/doc/cbo-1/cbd-cbo1-summary-en-f-web.pdf).

13. Tickle, A., Fergusson, M., Drucker, G., 1995. Acid Rain and Nature Conservation in Europe: A Preliminary Study of Protected Areas at Risk from Acidification. World Wildlife Fund International, Gland. 